Aspiration of gastric (acid) content is a major cause of acute respiratory failure that occurs in children with severe gastroesophageal reflux, gastrointestinal malformations, and neurologic impairment. Alveolar surfactant alterations were demonstrated in diseases with similar aetiology like ARDS and meconium aspiration syndrome. To understand if the surfactant system is modulated locally or if an unilateral injury influences both lungs, we measured alveolar surfactant DSPC in a murine model of unilateral acid injury.

We developed a mouse model of acid lung injury confined in a single lung (right). Deuterated water was injected $18 \mathrm{~h}$ after the lung injury and DSPC-palmitate deuterium enrichment was measured for the next 24 hours in BAL and tissue. MPO and total protein analysis was performed separately to each lung to assess the inflammatory status.

Inflammatory status of both lungs was markedly increased in the injured (right) lung. DSPC content was not significantly different between the two lungs in tissue homogenates at all time points $(1.83 \pm 0.3$ vs. $1.75 \pm 0.6 \mathrm{umol} / \mathrm{g}$ of lung). Conversely, DSPC content in BAL was significantly increased in the not-injured lung $(1.00 \pm 0.36$ vs. $1.49 \pm 0.5 \mathrm{umol} / \mathrm{g}$ of lung, $\mathrm{p}=0.008)$. Fractional synthetic rates did not significantly change in both homogenates and BAL between the two lungs.

These preliminary data suggest that surfactant system is likely to be regulated at the whole lung level. The not-injured lung seems to increase the amount of DSPC in the alveolar space as a compensatory mechanism for the damage in the contralateral lung.

\section{CLINICAL EFFECTIVENESS OF EARLY ADMINISTRATION OF CAFFEINE AND LOW-DOSE HYDROCORTISONE TO PRETERM NEWBORNS WITH A HIGH RISK OF BPD DEVELOPMENT}

doi:10.1136/archdischild-2012-302724.0405

'D Dobryanskyy, ${ }^{1,20}$ Borysiuk, ${ }^{2} Z$ Salabay, ${ }^{2} Y$ Dubrovna. ${ }^{1}$ Department of Pediatrics, L'viv National Medical University; ${ }^{2}$ Neonatal Intensive Care Unit, L'viv Regional Clinical Hospital, L'viv, Ukraine

Because intrauterine and/or early postnatal inflammation play(s) an important role in the pathogenesis of bronchopulmonary dysplasia (BPD) early administration of anti-inflammatory therapy to highrisk preterm newborns is theoretically substantiated. In a randomised study we evaluated the clinical effectiveness of early administration of caffeine and hydrocortisone to very preterm newborns that required mechanical ventilation (MV) shortly after birth. Methods 120 very low birth weight newborns (gestational age $<32$ wks.) on MV were randomly assigned on the first day of life to one of the 2 groups depending on administration of caffeine and hydrocortisone. 60 infants with gestational age of 28.02 (1.9) wks. were treated with caffeine $(20 / 5 \mathrm{mg} / \mathrm{kg} /$ day $)$ and hydrocortisone $(1 \mathrm{mg} / \mathrm{kg} /$ day) for 12 days. 60 babies with gestational age of 28.4 (1.8) wks. in the control group were managed according to standard guidelines. The primary study outcome was the incidence of mortality and BPD at 36 weeks' corrected age. BPD was defined according to the NIH consensus definition in modification of Walsh et al. (2003).

Results BPD developed in 19 (35\%) infants treated with caffeine and hydrocortisone and in $20(37 \%)$ babies from the control group ( $>0.05)$. The composite outcomes (death plus BPD) (26 [43\%] vs. 27 [45\%] accordingly; $p>0.05)$ and incidences of severe BPD were not different between the groups either. Early anti-inflammatory therapy reliably facilitated extubation but did not reduce the duration of the initial period of MV.

Conclusions Early administration of caffeine and hydrocortisone did not prevent BPD development in very preterm newborns requiring $M V$.

\section{THE COMBINED EFFECTS OF ANTENATAL INFLAMMATION AND BETAMETHASONE ON LUNG MORPHOMETRY IN A RAT}

doi:10.1136/archdischild-2012-302724.0406

1,2JM Lee, ${ }^{1,2} \mathrm{CW}$ Choi, ${ }^{2,3} \mathrm{HJ}$ Lee, ${ }^{1}{ }^{12} \mathrm{Bl}$ Kim, ${ }^{1} \mathrm{JA}$ Lee, ${ }^{1} \mathrm{EK}$ Kim, ${ }^{1} \mathrm{HS}$ Kim, ${ }^{1} \mathrm{JH}$ Choi. ${ }^{1}$ Department of Pediatrics, Seoul National University College of Medicine, Seoul; ${ }^{2}$ Medical Research Institute, Seoul National University Bundang Hospital, Seongnam; ${ }^{3}$ Department of Pediatrics, Hanyang University College of Medicine, Seoul, Republic of Korea

Aim To investigate the effects of antenatal maternal glucocorticoids on fetal lung inflammation by determining lung morphology and inflammatory cell influx in bronchoalveolar lavage fluid.

Methods Rat pups were divided into four experimental groups: vehicle (Control; $\mathrm{n}=18$ ), maternal betamethasone administration (Beta; $\mathrm{n}=16$ ), intra-amniotic lipopolysaccharide administration (LPS; n=18), or both betamethasone and lipopolysaccharide administration (Beta+LPS; $n=20$ ). The changes of lung morphometry were examined on day 5 and 14 and total and differential white cell counts were performed on the bronchoalveolar lavage (BAL) fluid at day 2 and 5 .

Results The Beta+LPS group showed marked inhibition of alveolarization, which was characterized by the larger and fewer distal air spaces at day 7 and sustained at day 14. The combination of betamethasone and LPS had significantly larger air spaces than the control, Beta and LPS groups and lower alveolar surface area than the control and LPS groups on day 14. Combination of betamethasone and LPS significantly decreased neutrophil counts in BAL fluid compared with LPS alone group on day 2, but the neutrophil counts were no longer decreased with a delayed clearance of the inflammation $(\mathrm{P}=0.041)$. On day 5 , the Beta+LPS group had significantly more neutrophils compared to the LPS group in BAL fluid $(\mathrm{P}=$ 0.004).

Conclusion Our results suggest that concurrent exposures of both betamethason and LPS in the fetal lung may modulate inflammatory responses to continal resulting in bronchopulmonary dysplasia.

\section{IS THE ASSOCIATION BETWEEN CHORIOAMNIONITIS AND ADVERSE REPIRATORY OUTCOMES A MYTH IN THE ERA OF ANTENATAL CORTICOSTEROIDS?}

doi:10.1136/archdischild-2012-302724.0407

'D Harding, ${ }^{2} \mathrm{~A}$ Howell, ${ }^{2 T}$ Candler, ${ }^{3} \mathrm{C}$ Platt. 'NICU St. Michael's Hospital Bristol; ${ }^{2}$ UHBristol NHS Trust; ${ }^{3}$ Dept of Paediatric Pathology, UHBristol NHS Trust, Bristol, UK

Background and Aims Chorioamnionitis has historically been associated with adverse neonatal respiratory outcomes. The outcomes of very low birthweight (VLBW) babies born in the UK with histological chorioamnionitis and treated with antenatal corticosteroids has not been examined. Our aim was to determine if there was an association between histological chorioamnionitis and adverse respiratory outcomes in our population of VLBW infants who received antenatal corticosteroids.

Methods 294 VLBW babies born between Jan 2001 and Dec 2010 who had received antenatal corticosteroids and had placental histology performed were identified. Infant characteristics and outcomes were as described by Vermont-Oxford. Analysis was performed using chi square, student t-test and logistic regression.

Results 97 babies out of 294 babies (33\%) had histological chorioamnionitis (58 had funisitis). Chorioamnionitis was associated with ventilation $73(85 \%) v 117(69 \%), p=0.006$, surfactant $72(84 \%)$ v $112(66 \%), p=0.003$, RDS 75 (87\%)v 120 (71\%), p=0.004, Steroids for CLD $6(7 \%) v 11(7 \%) \mathrm{p}=0.788$, All discharges on $\mathrm{O}_{2}$ (transfers \& home 02$) 44(51 \%) \vee 57(33 \%), p=0.007$. Chorioamnionitis was associated with the need for oxygen at 36 weeks $(52 \%$ v $31 \%$, OR 2.4 , p= $0.015)$. However the group of infants with chorioamnionitis were 
less mature than those without chorioamnionitis (mean age at birth $27 w k s \mathrm{v} 29$ wks, mean dif. $-2.2, \mathrm{p}<0.001$ ). After adjustment for gestation chorioamnionitis was not associated with respiratory sequele.

Conclusion In our population of VLBW infants treated with antenatal corticosteroids histological chorioamnionitis is not associated with adverse respiratory status. The most significant predictor of respiratory progress is gestational age.

\section{AEROSOLIZED SURFACTANT IMPROVES LUNG MECHANICS AND REDUCES LUNG INJURY IN PREMATURE LAMBS WITH RESPIRATORY DISTRESS SYNDROME}

doi:10.1136/archdischild-2012-302724.0408

${ }^{1} \mathrm{C}$ ReySantano, 'VE Mielgo, 'E Ruiz-del-Yerro, ${ }^{2} \mathrm{~L}$ Andres, ${ }^{3} \mathrm{~A}$ Vallsi-Soler, ${ }^{1} \mathrm{X}$ Murgia. ${ }^{1}$ Respiratory Physiology Research Unit; ${ }^{2}$ Pathology, University Cruces Hospital; ${ }^{3}$ Neonatal Intensive Care Unit, Cruces Hospital, Barakaldo, Spain

Background Aerosolization of surfactant(SF) has emerged as feasible alternative to instillation for RDS.

Aim To determinate the effects of aerosolized SF on lung function and evaluate changes in the biochemistry and histology of premature lung.

Methods 21 preterm lambs (85\%gestation) were randomly assigned to receive aerosolized SF (Curosurf $®$, 200mg/kg-20min), delivered via an inhalation catheter (SF-Aero), bolus-SF (SF-Bolus) or Control groups maintained during 6hours in IMV. Lung mechanics [compliance $\left(\mathrm{C}_{\mathrm{dyn}}\right)$ and tidal-volume $\left(\mathrm{V}_{\mathrm{T}}\right)$ ], antioxidant enzyme (catalase; superoxide-dismutase, SOD; gluthation-peroxidase, GSHPx) activity, surfactant proteins (SP-B, SP-C) concentration and histological analysis were performed. Mean \pm SD, ANOVA, $\mathrm{p}<0.05$. *vs. Control, \#vs.SF-bolus group.

Results After $60 \mathrm{~min}$ of treatment, animals in SF-Aero and SFBolus groups, significantly improved $\mathrm{C}_{\mathrm{dyn}}$ and $\mathrm{V}_{\mathrm{T}}$ in comparison to control group, being improvement persistent until the end of the experiment.

Abstract 408 Table 1 Biochemical lung analysis

\begin{tabular}{lccc}
\hline & CONTROL & SF-BOLUS & SF-AERO \\
\hline Catalase (U/ugDNA) & $6 \pm 1$ & $9 \pm 2^{*}$ & $8 \pm 5$ \\
SOD (U/ugDNA) & $10 \pm 5$ & $14 \pm 11$ & $9 \pm 5$ \\
GSH-PX (U/ugDNA) & $0.02 \pm 0.01$ & $0.03 \pm 0.01$ & $0.04 \pm 0.01$ \\
IL-8 (pg/mgproteine) & $18.7 \pm 5.2$ & $11.1 \pm 6.5$ & $11.3 \pm 3.1^{*}$ \\
SP-B (ng/mgproteine) & $3.0 \pm 0.6$ & $3.7 \pm 0.9$ & $3.4 \pm 0.6$ \\
SP-C (ng/mgproteine) & $10.4 \pm 4.1$ & $12.7 \pm 4.8$ & $15.9 \pm 4.2^{*}$ \\
\hline
\end{tabular}

Conclusion Surfactant delivered as an aerosol produce a similar response in terms of pulmonary mechanics to bolus instillation, and result in less lung damage.

\section{PREDICTIVE VALUE OF THE BAYLEY SCALES OF INFANT DEVELOPMENT ON DEVELOPMENT OF VERY PRETERM/ VERY LOW BIRTH WEIGHT CHILDREN: A META-ANALYSIS}

doi:10.1136/archdischild-2012-302724.0409
${ }^{1}$ ES Luttikhuizen dos Santos, ${ }^{2} \mathrm{JF}$ de Kieviet, ${ }^{2} \mathrm{M}$ Königs, ${ }^{1,3} \mathrm{RM}$ van Elburg, ${ }^{2} \mathrm{~J}$ Oosterlaan. ${ }^{1}$ Paediatrics, VU University Medical Center; ${ }^{2}$ Clinical Neuropsychology, VU University, Amsterdam; ${ }^{3}$ Danone Research Centre for Specialized Nutrition, Wageningen, The Netherlands

Background and Aims The Bayley Scales of Infant Development (BSID) is the most widely used measure to assess neurodevelopment of very preterm (gestational age $\leq 32$ weeks) and very low birth weight (VLBW, $\leq 1500$ grams) infants in the first three years of life. This meta-analysis determines the predictive value of the mental subscale (MDI) and motor subscale (PDI) of the BSID for later ( $\geq 36$ months) motor and cognitive development in very preterm/ VLBW children.

Methods PubMed, PsychINFO and CINAHL were searched for English-language peer-reviewed studies published before April 2012 Studies were included if they reported odds ratios or correlations between the MDI/PDI scores obtained in the first three years of life, and standardized intelligence or motor assessment in childhood ( $\geq 36$ months of age). Meta-analytic methods were applied to aggregate available data.

Results A total of 16 studies met inclusion criteria. Across 15 studies encompassing 1335 very preterm/VLBW children, MDI scores were strongly predictive for later cognitive development, $\mathrm{r}=0.61$ (95\%CI: 0.57-0.64), $\mathrm{p}<0.001$. The relationship between MDI scores and later cognitive development was not mediated by birth weight $(p=0.56)$, gestational age $(p=.70)$, and time interval between assessments $(p=0.55)$. Across four studies including 465 very preterm/ VLBW children, PDI scores were moderately predictive for later motor function, $\mathrm{r}=0.32$ (95\%CI: 0.22-0.40), $\mathrm{p}<0.001$.

Conclusions In very preterm/VBLW children, MDI scores explain $37 \%$ of the variance in later cognitive functioning, whereas PDI scores explain $10 \%$ of later motor development. Thus a large proportion of the variance remains unexplained, underlining the importance of enhancing prediction of developmental outcomes.

\section{PERINATAL INFECTION AND NEURODEVELOPMENTAL OUTCOME IN VERY PRETERM AND VERY LOW BIRTHWEIGHT INFANTS: A META-ANALYSIS}

doi:10.1136/archdischild-2012-302724.0410

${ }^{1}$ EOG van Vliet, ${ }^{2} \mathrm{JF}$ de Kieviet, ${ }^{2} \mathrm{~J}$ Oosterlaan, ${ }^{1,3} \mathrm{RM}$ van Elburg. 'Neonatology, VU University Medical Center; ${ }^{2}$ Clinical Neuropsychology, VU University Amsterdam, Amsterdam; ${ }^{3}$ Danone Research Center for Specialised Nutrition, Wageningen, The Netherlands

Backgrounds Very preterm birth and very low birth weight (VLBW) is associated with adverse neurodevelopmental outcome. Many very preterm/VLBW infants develop perinatal infections. This quantitative meta-analysis summarizes studies evaluating the effect of perinatal infections on neurodevelopmental outcome in this population.

Methods We searched Medline, PsychInfo, EMBASE and Web of Knowledge for studies on infections and neurodevelopmental outcome measured with Bayley Scales of Infant Development $2^{\text {nd }}$ edition (BSID-II) scores in very preterm/VLBW infants. Two authors independently reviewed, rated and abstracted data from each article.

Abstract 408 Table 2 Lung injury score

\begin{tabular}{|c|c|c|c|c|c|c|c|c|}
\hline & Atelectasis & Necrosis & Edema & $\begin{array}{c}\text { Alveolar } \\
\text { inflammation }\end{array}$ & $\begin{array}{l}\text { Insterstitial } \\
\text { inflammation }\end{array}$ & $\begin{array}{c}\text { Alveolar } \\
\text { hemorrhage }\end{array}$ & $\begin{array}{c}\text { Interstitial } \\
\text { hemorrhage }\end{array}$ & TOTAL \\
\hline Control & $1.7(1-3)$ & 0 & 0 & $1.73(0-3)$ & $1.14(0-2)$ & $0.77(0-2)$ & $0.95(0-1)$ & $6.25(4-9)$ \\
\hline SF-BOLUS & $1.0(0-3)^{*}$ & 0 & 0 & $1.19(0-3)$ & $1.06(0-2)$ & $1.63(0-3)^{*}$ & $1.13(0-2)$ & $5.93(2-11)$ \\
\hline SF-AERO & $0.67(0-2)^{*}$ & 0 & 0 & $0.62(0-2)^{*} \#$ & $0.75(0-2)^{*}$ & $1.04(0-2) \#$ & $1.0(0-2)$ & $4.0(1-7)^{*} \#$ \\
\hline
\end{tabular}

